University of Nebraska - Lincoln

DigitalCommons@University of Nebraska - Lincoln

$3-6-2020$

\title{
Functional Connectivity Evoked by Orofacial Tactile Perception of Velocity
}

Yingying Wang Dr.

Fatima Sibaii

Rebecca Custead

Hyuntaek Oh

Steven M. Barlow

Follow this and additional works at: https://digitalcommons.unl.edu/specedfacpub

Part of the Special Education and Teaching Commons

This Article is brought to you for free and open access by the Department of Special Education and Communication Disorders at DigitalCommons@University of Nebraska - Lincoln. It has been accepted for inclusion in Special Education and Communication Disorders Faculty Publications by an authorized administrator of DigitalCommons@University of Nebraska - Lincoln. 


\section{OPEN ACCESS}

Edited by:

Kazutaka Takahashi,

University of Chicago, United States

Reviewed by:

Christian Wallraven,

Korea University, South Korea

Yusuke Takatsuru,

Gunma University, Japan

Sanne Kikkert,

ETH Zürich, Switzerland

*Correspondence:

Yingying Wang

yingying.wang@unl.edu

Specialty section:

This article was submitted to

Perception Science,

a section of the journal

Frontiers in Neuroscience

Received: 07 October 2019

Accepted: 19 February 2020

Published: 06 March 2020

Citation:

Wang Y, Sibaii F, Custead R, Oh H and Barlow SM (2020) Functional Connectivity Evoked by Orofacial

Tactile Perception of Velocity.

Front. Neurosci. 14:182.

doi: 10.3389/fnins.2020.00182

\section{Functional Connectivity Evoked by Orofacial Tactile Perception of Velocity}

\author{
Yingying Wang ${ }^{1,2,3,4 *}$, Fatima Sibaii ${ }^{1,4}$, Rebecca Custead ${ }^{5}$, Hyuntaek $\mathrm{Oh}^{4,5}$ and \\ Steven M. Barlow ${ }^{2,4,5}$
}

\begin{abstract}
${ }^{1}$ Neuroimaging for Language, Literacy and Learning Laboratory, Department of Special Education and Communication Disorders, University of Nebraska-Lincoln, Lincoln, NE, United States, ${ }^{2}$ Center for Brain, Biology and Behavior, University of Nebraska-Lincoln, Lincoln, NE, United States, ${ }^{3}$ Nebraska Center for Research on Children, Youth, Families and schools, University of Nebraska-Lincoln, Lincoln, NE, United States, ${ }^{4}$ Biomedical Engineering, University of Nebraska-Lincoln, Lincoln, NE, United States, ${ }^{5}$ Communication Neuroscience Laboratory, Department of Special Education and Communication Disorders, University of Nebraska-Lincoln, Lincoln, NE, United States
\end{abstract}

The cortical representations of orofacial pneumotactile stimulation involve complex neuronal networks, which are still unknown. This study aims to identify the characteristics of functional connectivity (FC) evoked by three different saltatory velocities over the perioral and buccal surface of the lower face using functional magnetic resonance imaging in twenty neurotypical adults. Our results showed a velocity of $25 \mathrm{~cm} / \mathrm{s}$ evoked stronger connection strength between the right dorsolateral prefrontal cortex and the right thalamus than a velocity of $5 \mathrm{~cm} / \mathrm{s}$. The decreased FC between the right secondary somatosensory cortex and right posterior parietal cortex for $5-\mathrm{cm} / \mathrm{s}$ velocity versus all three velocities delivered simultaneously ("All ON") and the increased FC between the right thalamus and bilateral secondary somatosensory cortex for $65 \mathrm{~cm} / \mathrm{s}$ vs "All ON" indicated that the right secondary somatosensory cortex might play a role in the orofacial tactile perception of velocity. Our results have also shown different patterns of FC for each seed (bilateral primary and secondary somatosensory cortex) at various velocity contrasts ( 5 vs $25 \mathrm{~cm} / \mathrm{s}, 5$ vs $65 \mathrm{~cm} / \mathrm{s}$, and 25 vs $65 \mathrm{~cm} / \mathrm{s}$ ). The similarities and differences of FC among three velocities shed light on the neuronal networks encoding the orofacial tactile perception of velocity.

Keywords: functional connectivity, orofacial, pneumotactile stimulation, fMRI, saltatory velocity, cortical representation

\section{INTRODUCTION}

The human somatosensory system decodes tactile stimuli from peripheral sensory receptors through a complex process involving interactions between bottom-up thalamocortical and topdown corticocortical/cortico-thalamo-cortical pathways (Avivi-Arber et al., 2011; Lundblad et al., 2011; Zembrzycki et al., 2013; Hwang et al., 2017). Studies of cortical representations of tactile stimulation of different body parts have identified the primary (SI) and secondary (SII) somatosensory cortices, as well as the supplementary motor area responsible for sensory processing (Ibáñez et al., 1995; Backes et al., 2000; Grodd et al., 2001; Backlund et al., 2003; Paus et al., 2006; Backlund Wasling et al., 2008; Bjornsdotter et al., 2009; Ackerley et al., 2012; Zembrzycki et al., 2013; Akselrod et al., 2017; Custead et al., 2017; Oh et al., 2017; Yeon et al., 2017). SI, which is 
located in the postcentral gyrus, processes complex information about the location, velocity, and other characteristics of tactile stimulation from the thalamus through the thalamocortical axons. Damage to the SI (e.g., by stroke, traumatic brain injury, etc.) could result in orofacial sensory and motor deficits; the recovery of such damage to the sensorimotor system requires characterizing the neuronal connections (both structural and functional connectivity) (Nudo, 2013). Therefore, the neuronal connections among cortical regions are critical for understanding the cortical plasticity after injuries to the somatosensory system.

Tactile sensation is detected by cutaneous mechanoreceptors in the skin and is then projected to afferent neurons or sensory nerves, via the spinal cord, toward the central nervous system (Jenkins and Lumpkin, 2017). Pacinian corpuscles, a type of cutaneous mechanoreceptors that usually detect rapid vibrations (about 200-300 Hz) in both glabrous and hairy skin (e.g., palm and arm, respectively), were considered to be virtually absent from the facial skin based on psychophysical methods (Barlow, 1987), and the cutaneous mechanoreceptors in the facial skin have high densities and are slow adapting, with small receptive fields (Johansson and Olsson, 1976; Johansson et al., 1988).

Vibrotactile adaption has been observed in both the hands and face (Hollins et al., 1991). Individual mechanoreceptors in the facial skin responded differently to brush stimuli moving at different velocities (Edin et al., 1995). Nevertheless, it has been argued that the central nervous system might not be able to decode velocity of movement across the skin in humans (Edin et al., 1995). However, animal studies have suggested that rat SI neurons could process complex tactile stimuli such as direction and velocity of motion (Moore et al., 1999; Krupa et al., 2001; Ferezou et al., 2007; Tomita et al., 2012; Zembrzycki et al., 2013). Furthermore, neuroimaging studies also indicated that there are different cortical representations for different tactile stimuli in humans (e.g., location, type of motion, direction, velocity, etc.) (Reed et al., 2004; Miyamoto et al., 2006; Backlund Wasling et al., 2008; Eickhoff et al., 2008; Bjornsdotter et al., 2009; Moulton et al., 2009; Avivi-Arber et al., 2011; Grabski et al., 2012; Huang et al., 2012; Khoshnejad et al., 2014; Yang et al., 2014; Custead et al., 2015, 2017; Hwang et al., 2017; Oh et al., 2017; Yeon et al., 2017).

The cross-modality plasticity theory suggested that somatosensory stimuli could evoke neural responses to promote learning of new motor skills (Sanes and Donoghue, 2000; Nasir et al., 2013; Ladda et al., 2014) and performing motor tasks more accurately (Pearson, 2000). The integration of the orofacial sensory and motor system has been suggested to be critical for motor learning and motor control for sucking, swallowing, and producing speech sounds (Barlow and Bradford, 1996; Barlow, 1998; Sessle et al., 2005, 2007; Barlow and Estep, 2006; Barlow and Stumm, 2010; Smith, 2016). If passive pneumotactile stimulation could effectively evoke changes in the neuronal connections and positively impact motor learning, there may be a paradigm shift in early neurorehabilitation protocols to improve functional recovery after brain injury (e.g., due to stroke, traumatic brain injury, etc.).

The cortical representations of moving tactile stimulation have mostly been investigated on the hand. Brushing over the right thumb once every one and a half second and using electric stimuli to the median nerve in seven healthy participants, Lin et al. identified the different shapes of waveforms of somatosensory evoked fields in SI using magnetoencephalography (MEG) (Lin and Kajola, 2003). A functional magnetic resonance imaging (fMRI) study compared active touch, self-touch, and passive touch of both the glabrous palm and hairy arm, using a stroking velocity between 6 and $8 \mathrm{~cm} / \mathrm{s}$ and demonstrated specialization of cortical regions for processing of somatosensory information (Ackerley et al., 2012). They found that moving tactile stimulation of the glabrous palm activated more extensive cortical areas of the right SI (subarea Brodmann area BA 3, contralateral) than that of the hairy arm. Moreover, active stroking evoked positive blood-oxygenation level dependent (BOLD) signals in the left SI (ipsilateral), whereas passive stroking evoked negative BOLD signals. More recently, a fMRI study identified the left SI, left superior temporal gyrus (STG), and the left precentral gyrus (preG) as being involved in encoding saltatory pneumotactile velocity stimulation of the glabrous hand, using stimuli at 5,25 , and $65 \mathrm{~cm} / \mathrm{s}$ (Oh et al., 2017). The velocity of $25 \mathrm{~cm} / \mathrm{s}$ evoked the most extensive BOLD signal among all velocity settings.

However, for the face, the cortical representations of moving tactile stimulation have not been well studied. Not knowing the neural subtracts of perceiving moving stimulation on the face has limited our understanding of velocity and directional encoding in the sensory domain. In our previous fMRI study, we identified a putative neural somatosensory velocity network with bilateral SI, bilateral cerebellum, bilateral middle occipital gyrus, left MI, right SII, right STG, and right SMG, right inferior frontal gyrus (IFG), which had not been reported previously (Custead et al., 2017). Custead et al. used a univariate generalized linear model (GLM) to determine brain regions with specific responses to the pneumotactile stimulation at each voxel. The univariate GLM approach assumes that each voxel in the brain is functionally specialized rather than functionally integrated (Stephan et al., 2006). However, this perspective limits our understanding of how different brain regions communicate with each other, which is essential for understanding complex neuronal networks (Tononi et al., 1998). Task-based functional connectivity (FC) measured by evaluating the correlation between time series of BOLD signals among brain regions does not measure structural connections (e.g., axonal projections), but represents the functional coupling between two or more spatially or anatomically distinct areas of the brain (Stevens, 2009; Hermundstad et al., 2013). To date, little is known about the functional connectivity (FC) evoked by the orofacial tactile perception of velocity.

The present study therefore aimed to identify the characteristics of FC evoked by pneumotactile stimuli, at three saltatory velocities $(5,25$, and $65 \mathrm{~cm} / \mathrm{s})$, on the nonglabrous lower face, as an extension to our previous work, in order to enhance our understanding of the neural networks responsible for encoding the velocity of tactile stimulation (Custead et al., 2017). We hypothesized that there would be different patterns of FC corresponding to the three velocities.

The pneumotactile stimulator used in this study (Galileo ${ }^{\mathrm{TM}}$ ) overcomes the technical challenges of automatically applying 
tactile stimulation to the face without eliciting pain sensation during fMRI (Custead et al., 2017). A single chambered tactile cell (TAC-Cell) or multiple TAC-Cells of the Galileo system can be placed on both glabrous and hairy skin through adhesive tape collars, and are compatible with many neuroimaging techniques, such as MRI, functional near-infrared spectroscopy (fNIRS), MEG, and electroencephalography (EEG). The in-house computer software allows the Galileo system to deliver saltatory tactile stimuli at a variety of settings (amplitude, velocity, etc.). Unlike other pneumotactile stimulators (Dresel et al., 2008; Huang et al., 2012), the Galileo with TAC-Cells is easy to set up and program for various applications. This pneumotactile stimulator has been used to examine the neural subtracts of the human somatosensory system and has effectively activated SI, SII, and the PPC (Popescu et al., 2013; Custead et al., 2017; Oh et al., 2017).

Based on our previous work and other studies in the literature (Blatow et al., 2007; Huang et al., 2012; Custead et al., 2017), we here chose 10 regions-of-interest (ROIs), including the bilateral SI, SII, PPC, dorsolateral prefrontal cortex, and thalamus for hypothesis-driven ROI-to-ROI FC analysis, to examine whether the FC of our hypothesized networks differ across the three stimulation velocities. Then, four ROIs, including the bilateral SI and SII, were chosen for data-driven Seed-to-Voxel FC analysis to examine which cortical areas are functionally connected to either SI or SII, and whether this differ across the three stimulation velocities.

\section{MATERIALS AND METHODS}

\section{Participants}

Twenty healthy, right-handed, native English-speaking adults (15 females), $18-30$ years of age (mean \pm SD: $22.3 \pm 1.7$ ), agreed to participate in the study after providing written informed consent. All participants reported the right hand as the preferred hand and had no history of neurological or psychiatric disorders, or any chronic illness or scheduled medications. The study was approved by the Institutional Review Board at the University of Nebraska-Lincoln.

\section{Stimulus Device}

Pneumotactile stimuli were delivered to the facial skin by a multichannel pneumatic amplifier and tactile array known as the Galileo Somatosensory ${ }^{\mathrm{TM}}$ system (Epic Medical Concepts \& Innovations, Inc., Mission, Kansas, KS, United States). The Galileo system utilizes TAC-Cells made from acetyl thermoplastic homopolymer, which uses tiny volumes of compressed air to deform the surface of the skin rapidly. The TAC-Cells are MRIsafe and incorporate a small capsule with a sealing flange. In Figure 1, the placement of seven TAC-Cells on a representative participant was shown from the upper and lower lips to the right lateral cheek of the face. Before using double-adhesive tape collars to secure each TAC-Cell, ten percent concentration of tincture of Benzoin was applied to the skin for improvement of adhesion. For each participant, the distances between each TAC-Cell were measured and taken into consideration for designing the velocity trains traversing in a repeating medial-to-lateral direction on the face. For all conditions, the Galileo system was programed to generate biphasic pulses with a duration of $60 \mathrm{~ms}$, frequency of $1 \mathrm{~Hz}, 10 \mathrm{~ms}$ rise/fall, amplitude from -5 to $28 \mathrm{kPa}$ (Custead et al., 2017; Oh et al., 2017). Our in-house software program generated air pressure pulses to five channels sequentially for $5,25,65 \mathrm{~cm} / \mathrm{s}$ conditions and simultaneously for "All ON" condition. The Galileo system was located outside the MRI suite and delivered pneumotactile stimuli through polyurethane tubing into the MRI suite. Participants described the sensory experience as a moving sequence of discrete 'taps' or 'raindrops' on their lower face without any discomfort (Custead et al., 2017).

\section{Paradigms}

We used a block design, and each twenty-second task block was followed by a twenty-second resting block (Custead et al., 2017; Oh et al., 2017) (see Figure 2). The twenty-second block of either $5 \mathrm{~cm} / \mathrm{s}$, or $25 \mathrm{~cm} / \mathrm{s}$, or $65 \mathrm{~cm} / \mathrm{s}$, or “All ON", or “All OFF” was randomized. The different velocities represented the different speeds of the air pressure pulses traveling (saltation) through channels (see Figure 1). For instance, the $5 \mathrm{~cm} / \mathrm{s}$ represented that the air pressure pulses went through all channels sequentially within approximately $5 \mathrm{~s}$ in total (starting at channel 1 , about $1 \mathrm{~s}$ at channel 2, $2 \mathrm{~s}$ at channel $3,3 \mathrm{~s}$ at channel 4 , and about $5 \mathrm{~s}$ at channel 5). The $25 \mathrm{~cm} / \mathrm{s}$ meant that the pressure pulses went through all channels sequentially within approximately $2 \mathrm{~s}$ in total. The $65 \mathrm{~cm} / \mathrm{s}$ represented that the air pressure pulses went through all channels sequentially within about $1.5 \mathrm{~s}$ in total. The "All ON" indicated that the air pressure pulses went through all channels simultaneously. The "All OFF" meant that no air pressure pulse went through all channels, which is equivalent to the resting period. During the fMRI scan, visual countdown task was used to maintain the participants' vigilance using E-Prime 2.0 software (Psychology Software Tools, Pittsburgh, PA, United States). The participants were directed to pay attention to the number shown on the screen for only $0.5 \mathrm{~s}$ to minimize brain activation in the primary visual cortex. A declining countdown from 20 to 1 represented the remaining time in seconds for the tactile stimulation.

\section{Data Acquisition}

All images were acquired on a $3.0 \mathrm{~T}$ Siemens Skyra wholebody MRI system (Siemens Medical Solutions, Erlangen, Germany) with a 32-channel head coil. A high-resolution T1-weighted three-dimensional anatomical scan was acquired using magnetization-prepared rapid gradientecho sequences (MPRAGE) with the following parameters: $\mathrm{TR} / \mathrm{TE} / \mathrm{TA}=2.4 \mathrm{~s} / 3.37 \mathrm{~ms} / 5: 35 \mathrm{~min}$, flip angle $=7^{\circ}$, field of view $=256 \times 256 \mathrm{~mm}$, spatial resolution $=1 \times 1 \times 1 \mathrm{~mm}^{3}$, number of slices $=192$. Following the MPRAGE anatomical scan, three sessions of functional MRI (fMRI) scans were recorded using a $\mathrm{T}^{*}$-weighted echo planar imaging (EPI) sequence with the following parameters: TR/TE/TA $=2.5 \mathrm{~s} / 30 \mathrm{~ms} / 800 \mathrm{~s}$, voxel size $=2.5 \times 2.5 \times 2.5 \mathrm{~mm}^{3}$, flip angle $=83^{\circ}$, number of slices $=41$, number of volumes $=320$. 


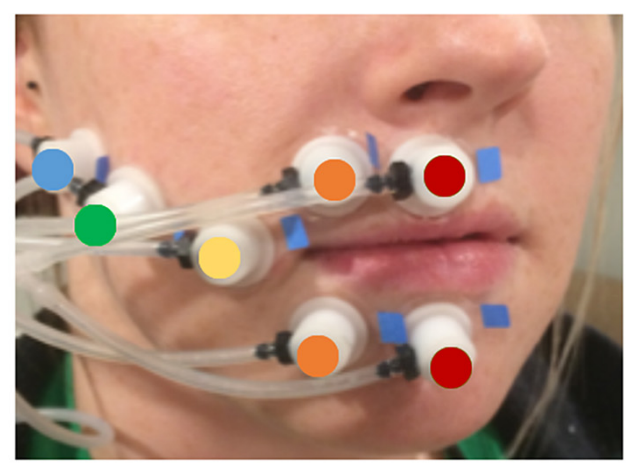

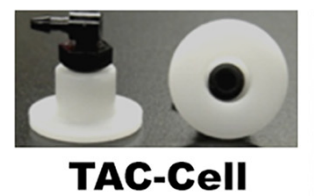

Channel 1

Channel 2

Channel 3

Channel 4

Channel 5

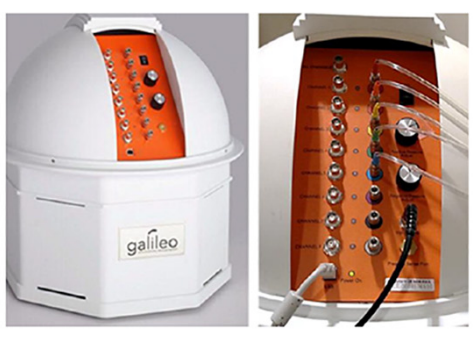

Galileo $^{\text {TM }}$
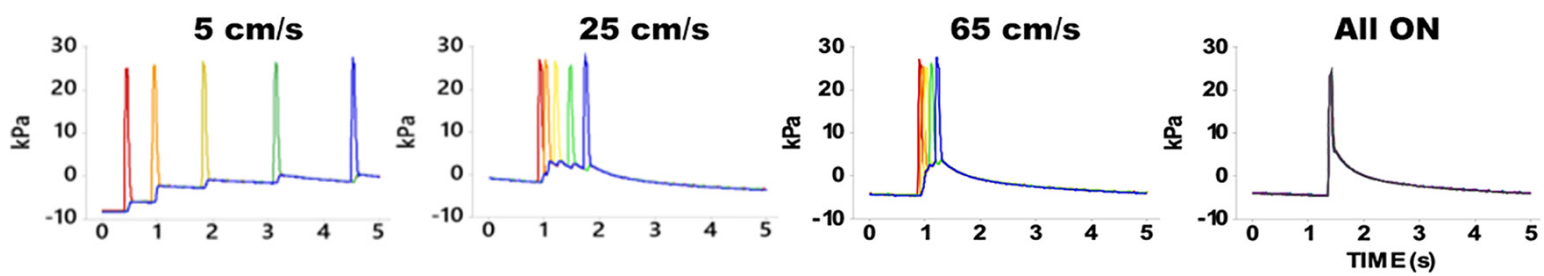

FIGURE 1 | Shows the experimental configuration for the Galileo somatosensory stimulator with pneumatic velocity arrays aligned on the participant from the right philtral column to the right buccal face. White flanged surface of the TAC-Cell was adhered to skin surface with double adhesive colars and 7 TAC-Cells form 5 channels in five colors (red: channel 1 placed two TAC-Cells on the median upper and lower lips; orange: channel 2 placed two TAC-Cells next to the TAC-Cells of channel 1; yellow: channel 3 placed a TAC-Cells next to the channel 2; green: channel 4 placed a TAC-Cell next to channel 3; blue: channel 5 placed a TAC-Cell next to channel 4). The bottom four graphs show the time courses for each velocity and All ON.

\section{Each Run consists of twenty $\mathbf{4 0 - s}$ block (4 blocks for each condition).

\begin{tabular}{|c|c|c|c|c|c|c|c|c|c|}
\hline $5 \mathrm{~cm} / \mathrm{s}$ & & $25 \mathrm{~cm} / \mathrm{s}$ & & All ON & & $65 \mathrm{~cm} / \mathrm{s}$ & & & \\
\hline & Rest & & Rest & & & & Rest & All OFF & Rest \\
\hline
\end{tabular} \\ a block}

FIGURE 2 | One run of the fMRI in-scan paradigm indicates a series of pneumotactile saltatory stimuli traversed the skin in a repeating medial-to-lateral direction. There are twenty $40 \mathrm{~s}$ long blocks in one run. Each block consisted of one 20 s block of task stimuli presentation and $20 \mathrm{~s}$ block of rest. There are five possible task blocks $(5,25,65 \mathrm{~cm} / \mathrm{s}$, All ON, All OFF) randomly presented.

The first TR pulse from the MRI scanner during fMRI data acquisition went through a Berkeley Nucleonics pulse generator (Model 645), which was in charge of sending triggers to the Galileo system to produce a velocity sequence every $40 \mathrm{~s}$. The Galileo system generated a velocity condition for $20 \mathrm{~s}$, then wait for $20 \mathrm{~s}$ to initiate the next velocity sequence. To reduce the effect of fatigue, we did three runs separately and gave optional breaks between runs. Each run consisted of 20 blocks, and 20 blocks consisted of four sets of randomly presented five conditions (5, 25, $65 \mathrm{~cm} / \mathrm{s}$, “All ON”, "All OFF”) (see Figure 2). Each run includes four blocks of $5 \mathrm{~cm} / \mathrm{s}$ ( $80 \mathrm{~s}$ and $52 \mathrm{TR}$ ), four blocks of $25 \mathrm{~cm} / \mathrm{s}$ (80 s and $52 \mathrm{TR}$ ), four blocks of $65 \mathrm{~cm} / \mathrm{s}$ (80 s and 52 TR), four blocks of "All ON" (80 s and 52 TR), four blocks of "All OFF" (80 s and 52 TR). In total, each condition block lasted $960 \mathrm{~s}$ with $480 \mathrm{~s}$ condition segment and $480 \mathrm{~s}$ rest segment. Nineteen participants completed all three runs, while one participant only completed two runs.

\section{Data Analysis}

The CONN toolbox (Whitfield-Gabrieli and Nieto-Castanon, 2012) ${ }^{1}$ was used for pre-processing all images and compute brain connectivity using both seed-based and region-of-interests (ROIs)-based approaches. The CONN toolbox used Statistical Parametric Mapping $\left(\mathrm{SPM}_{12}{ }^{2}\right)$ toolbox to pre-process all image volumes, including functional realignment, structural segmentation and normalization, ART-based scrubbing, and smoothing. First, the functional data were realigned to the first scan and to correct for interscan head movement. The functional realignment process in the CONN toolbox automatically generated the first-level covariate with six rigidbody parameters that quantified the estimated motion for each participant and each run. The functional realignment covariate

\footnotetext{
${ }^{1}$ http://www.nitrc.org/projects/conn

${ }^{2}$ https://www.fil.ion.ucl.ac.uk/spm/software/spm12/
} 
can be used in the GLM to regress out the residual movementrelated effects from the time series. Second, the structural image was segmented into gray matter (GM), white matter (WM), and cerebrospinal fluid (CSF) in the individual participant's space, and normalized to the Montreal Neurological Institute (MNI) space. The transformation matrix between the segmented MRI to MNI space was saved and used to coregister functional images to the normalized structural MRI. The Artifact Rejection Toolbox $\left(\mathrm{ART}^{3}\right)$-based scrubbing built-in CONN toolbox was applied to outlier detection and scrubbing to compute confound regressors using default parameters (global threshold: 9 stand-deviations above or below the mean, motion threshold: $2 \mathrm{~mm}$ translation and $2^{\circ}$ rotation in any direction). The ART-based scrubbing technique detected an outlier if the largest voxel movement between volumes exceeded the thresholds. Only three outliners were identified and treated as nuisance regressors in the first-level GLM analysis. Finally, all coregistered fMRI data were smoothed with an isotropic Gaussian kernel of $8 \mathrm{~mm}$ full-width-at-halfmaximum (FWHM).

The task-related functional connectivity was computed in the CONN toolbox. For each participant, CONN implemented CompCor to identify the top five principal components associated with segmented WM and CSF (Behzadi et al., 2007). These components were entered as confounds along with realignment parameters and nuisance regressors from ART-based scrubbing in the first-level GLM analysis. The residual time courses were linearly detrended (no despiking) and temporally filtered using a band-pass filter (0.008-0.09 Hz) during the denoising process in the CONN toolbox.

For the ROI-to-ROI analyses, we studied FC between ROIs for different velocities $(5,25,65 \mathrm{~cm} / \mathrm{s}$, “All ON”). We computed the strength and significance of bivariate Pearson correlation among pairs of ten ROIs for each participant. Five bilateral ROIs (see Table 1) were created using MNI coordinates in the CONN toolbox and the MNI coordinates were based on our previous work (Custead et al., 2017; Oh et al., 2017). The ROI-to-ROI correlation coefficients were obtained by calculating all possible correlation coefficients between the time series of each pair of ROIs. For ROI-to-ROI connectivity, significant connections were identified by calculating the False Discovery Rate (FDR)corrected two-sided p-value $(q)$ at $q<0.05$ thresholds for seed-level correction. The FDR seed-level correction applied FDR separately for each ROI and corrected across the multiple comparisons from having multiple target ROIs.

For seed-based FC analyses, a whole-brain approach was used to identify cortical areas that were differentially connected with bilateral SI and SII among four conditions $(5,25,65 \mathrm{~cm} / \mathrm{s}$, and "All ON"). The four seeds (see Table 1) were chosen based on the literature (Lin and Kajola, 2003; Pastor et al., 2004; Reed et al., 2004; Dresel et al., 2008; Ackerley et al., 2012; Popescu et al., 2013; Custead et al., 2017; Oh et al., 2017; Yeon et al., 2017) because bilateral SI and SII were most consistently identified across imaging studies with different parameters. We chose to compute all possible cross-correlation coefficients between the time series of the seeds and all residual voxels in the brain, and

${ }^{3}$ http://www.nitrc.org/projects/artifact_detect/
TABLE 1 | Regions Of Interest.

\begin{tabular}{|c|c|c|c|c|}
\hline \multirow[t]{2}{*}{ Name } & \multirow[t]{2}{*}{ Description } & \multicolumn{3}{|c|}{ Coordinates in MNI space } \\
\hline & & $X(\mathrm{~mm})$ & $Y(\mathrm{~mm})$ & $Z(\mathrm{~mm})$ \\
\hline \multicolumn{5}{|l|}{ Left hemisphere } \\
\hline Left SI & ROI \& Seed & -55 & -19 & 24 \\
\hline Left SII & ROI \& Seed & -48 & -24 & 16 \\
\hline Left PPC & $\mathrm{ROI}$ & -56 & -31 & 32 \\
\hline Left DLPFC & ROI & -27 & 32 & 36 \\
\hline Left Thalamus & ROI & -9 & -17 & 6 \\
\hline \multicolumn{5}{|c|}{ Right hemisphere } \\
\hline Right SI & ROI \& Seed & 56 & -13 & 29 \\
\hline Right SII & ROI \& Seed & 48 & -24 & 16 \\
\hline Right PPC & $\mathrm{ROI}$ & 56 & -31 & 32 \\
\hline Right DLPFC & $\mathrm{ROI}$ & 30 & 35 & 34 \\
\hline Right Thalamus & $\mathrm{ROI}$ & 10 & -19 & 6 \\
\hline
\end{tabular}

MNI, Montreal Neurological Institute; ROI, region of interest; SI, primary somatosensory cortex; SII, supplementary somatosensory cortex; PPC, Posterior Parietal Cortex; DLPFC, dorsolateral Prefrontal Cortex.

then convert them to $Z$-scores. At the second-level analysis in the CONN toolbox, we compared FC patterns among different tactile stimuli. To control for multiple comparison, the CONN toolbox implemented the Cluster Size Statistic (CSS) (Ing and Schwarzbauer, 2014). FC maps between all voxel pairs for all participants under all conditions were generated, and then $T$-statistics were calculated between connectivity values taken under different velocity conditions. A cluster-forming threshold was set at voxel-level $p<0.001$ and CSS only counted those with cluster-level FDR-corrected $p<0.05$ as significant, which is a multiple-comparison correction at the whole-brain level to control the false discoveries among significant clusters below 5\% rate (Friston et al., 1994).

\section{RESULTS}

\section{ROI-Based FC}

In Figure 3, functional networks for each velocity $(5,25$, and $65 \mathrm{~cm} / \mathrm{s}$ ) were overlaid onto three-dimensional rendered brain on the first row and task-related FC matrices for each velocity were plotted on the second row. Comparing 5 and $25 \mathrm{~cm} / \mathrm{s}$ task conditions, increased FC was identified between the right DLPFC and the right thalamus (see Figure 4). There is no significant difference of FC between 5 and $65 \mathrm{~cm} / \mathrm{s}$ and between 25 and $65 \mathrm{~cm} / \mathrm{s}$ for all ROI-to-ROI pairs. The contrast of $5 \mathrm{~cm} / \mathrm{s}$ vs "All ON" task condition showed significant decreased FC between the right SII and the right PPC and the contrast $65 \mathrm{~cm} / \mathrm{s}$ vs "All ON" task condition revealed increased FC between the right thalamus and the left SII and between the right thalamus and the right SII (see Figure 5).

\section{Seed-Based FC}

The seed-to-voxel analyses assessed FCs between four seed regions covering bilateral SI and SII and all other voxels in the brain (cluster size $>35$, cluster size FDR-corrected). In Table 2 

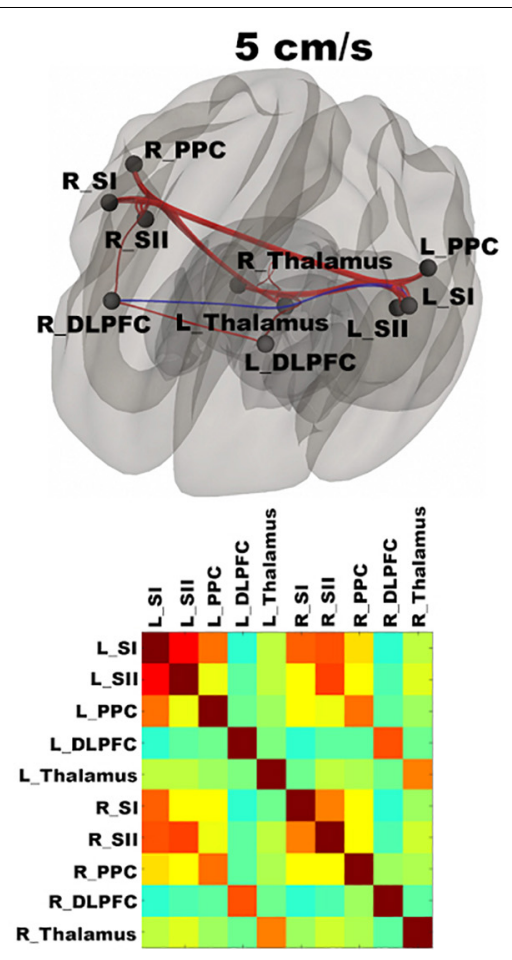
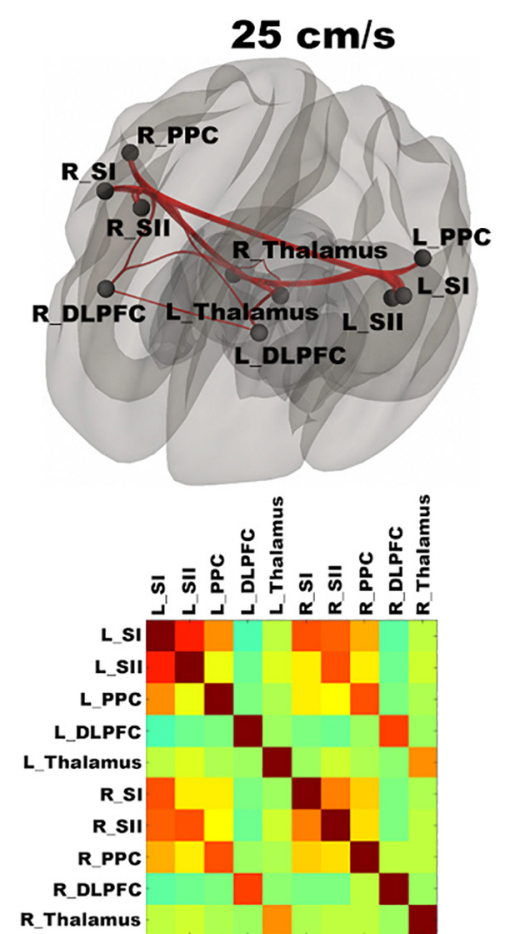
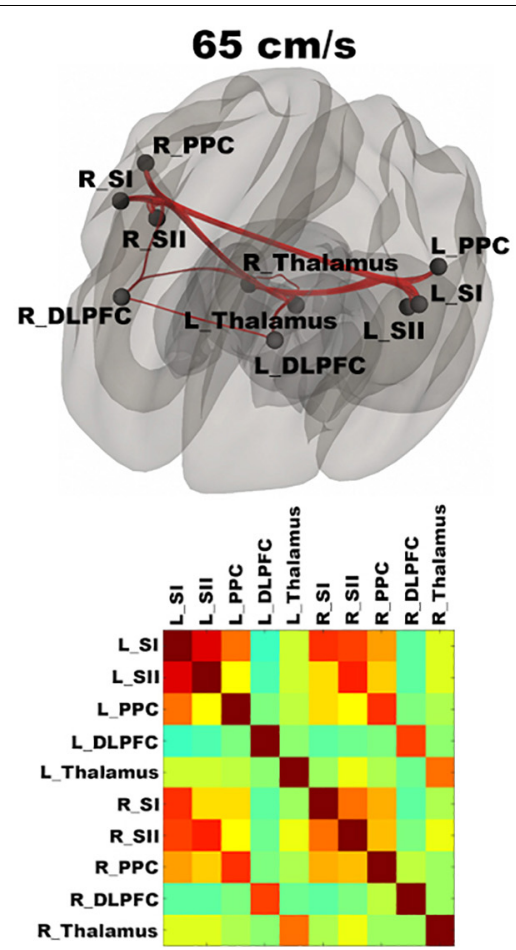

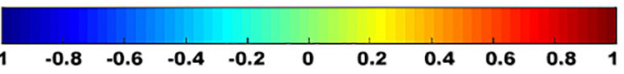

FIGURE 3 | Shows ROI-to-ROI based connectivity maps (first row) and connectivity adjacent matrices (second row) for three velocities (5, 25, $65 \mathrm{~cm} / \mathrm{s}$ ). Total six region of interests (ROIs) include bilateral primary somatosensory cortex (L_SI and R_SI), bilateral supplementary somatosensory cortex (L_SII and R_SII), bilateral Posterior Parietal Cortex (L_PPC and R_PPC), bilateral dorsolateral Prefrontal Cortex (L_DLPFC and R_DLPFC), and bilateral thalamus (L_Thalamus and

R_Thalamus). The color bar ranges from -1 to 1 and indicates the connectivity strength measured by Pearson's correlation coefficients. On the connectivity maps, the ROls are in block dots and positive connections are in red and negative connections are in blue. The thickness of the line is determined by the connectivity strength.

and Figure 6, for the left SI seed, results revealed increased FC in the left PostCG and left SMG for $5>25 \mathrm{~cm} / \mathrm{s}$, in the right pMTG, right cerebellum 6 , and right $A G$ for $5>65 \mathrm{~cm} / \mathrm{s}$, in the bilateral

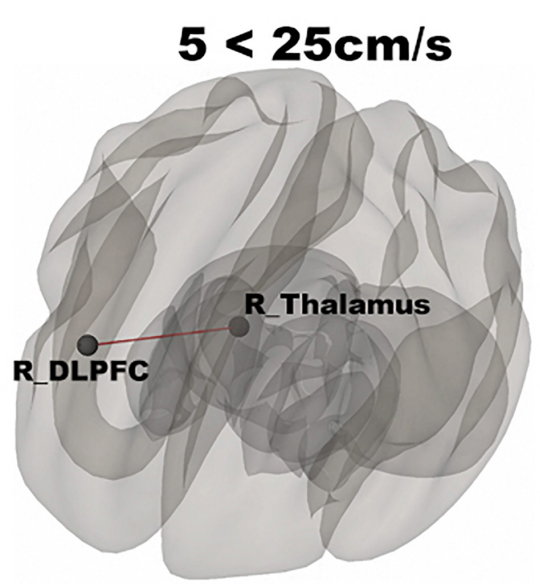

FIGURE 4 | Shows significantly increased connectivity between the right thalamus and right DLPFC for $5<25 \mathrm{~cm} / \mathrm{s}$.
iLOC, right sLOC, right FG, right Cerebellum 6 for $25>65 \mathrm{~cm} / \mathrm{s}$. For the left SII seed, increased FCs were only in the left SPL and right sLOC for $25>65 \mathrm{~cm} / \mathrm{s}$. In Table 2 and Figure 7, for the right SI seed, increased FCs were shown in the left iLOC and right pMTG along with decreased FCs in the right IC for $5>65 \mathrm{~cm} / \mathrm{s}$, and increased FCs were also observed in the bilateral iLOC along with decreased FC in the left cerebellum crus II for $25>65 \mathrm{~cm} / \mathrm{s}$. For the right SII seed, decreased FC was present in the right SFG for both $5>65 \mathrm{~cm} / \mathrm{s}$ and $25>65 \mathrm{~cm} / \mathrm{s}$. Additionally, increased FCs were shown in the left SPL and sLOC for $25>65 \mathrm{~cm} / \mathrm{s}$.

\section{DISCUSSION}

The present study examined FC evoked by the orofacial tactile perception of velocity using fMRI in 20 neurotypical adults. This study attempted to identify FC evoked by novel saltatory pneumotactile stimuli using TAC-Cells with the Galileo system, which has not been reported previously. Our findings suggested that there were more similarities in ROI-to-ROI neuronal networks in the contralateral cortical areas (on the opposite side to the stimuli) and more differences in FC patterns in the ipsilateral cortical areas (on the same side as the stimuli). The $5 \mathrm{~cm} / \mathrm{s}$ velocity evoked weaker FC between the right thalamus 


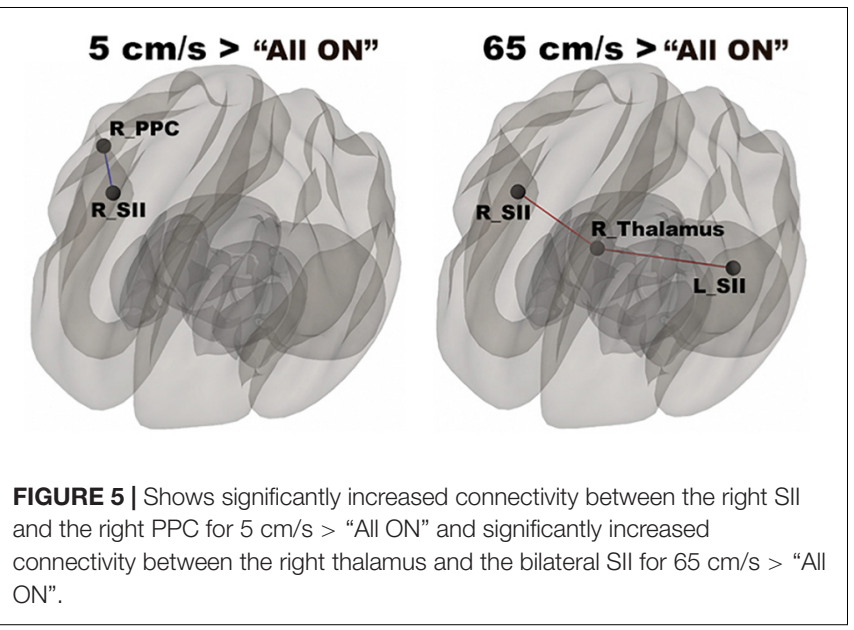

and the right DLPFC than did the $25 \mathrm{~cm} / \mathrm{s}$ velocity, indicating that a velocity of $25 \mathrm{~cm} / \mathrm{s}$ evoked stronger FC in the ipsilateral cortical regions. During the "All ON" condition, all TAC-Cells were stimulated simultaneously at $1 \mathrm{~Hz}$, without varying velocity. The decreased FC between the right SII and right PPC for contrasting $5 \mathrm{~cm} / \mathrm{s}$ with the "All ON" condition, and the increased FC between the right thalamus and bilateral SII for contrasting $65 \mathrm{~cm} / \mathrm{s}$ with the "All ON" condition, demonstrated the FC pattern evoked by orofacial tactile perception of velocity. Our Seed-to-Voxel approach identified different cortical network patterns for each seed at various velocity contrasts ( 5 vs $25 \mathrm{~cm} / \mathrm{s}$, 5 vs $65 \mathrm{~cm} / \mathrm{s}$, and 25 vs $65 \mathrm{~cm} / \mathrm{s}$ ), suggesting that specialized FC patterns are responsible for discriminating different velocities of orofacial tactile stimuli.

\section{Effects of Velocity}

In this study, the right side of the lower face was passively stimulated with air pulses from a spatial array of TAC-Cells, which produced a $2-3 \mathrm{~mm}$ deflection of the skin surface. Unlike the glabrous hand, the facial skin is non-glabrous and lacks Pacinian afferents (Barlow, 1987). Hairy skin also lacks Meissner afferents and contains both slowly conducting unmyelinated C-tactile afferents and fast-conducting myelinated $\mathrm{A} \beta$ fibers (Nordin, 1990; Ackerley et al., 2014). The Merkel afferents, a population of slow-adapting type 1 (SA1) afferents, were stimulated in the right lower face, and then their first-order afferents produced action potentials, which were carried by the first-order $A \beta$ axons into the ipsilateral main sensory trigeminal nucleus to release neurotransmitters to the second-order afferents. The second-order afferents generated action potentials that were conducted by their axons into the contralateral pons, to the ventral trigeminal lemniscus. The action potentials arrived at the contralateral thalamus and released neurotransmitters to the third-degree afferents in the core of the ventral posteromedial nucleus (VPM) of the thalamus. Finally, the third-degree VPM afferents released neurotransmitters to the cortical neurons in the SI and initiated the higher-order processing of the spatiotemporal information about the tactile stimuli delivered to the face (Norrsell and Olausson, 1994; Lundblad et al., 2011).
TABLE 2 | Seed-to-voxel results of changes in functional connectivity related to each velocity.

\begin{tabular}{|c|c|c|c|c|}
\hline \multirow[t]{2}{*}{ Region } & \multicolumn{3}{|c|}{ Coordinates in MNI space } & \multirow[t]{2}{*}{ Voxels } \\
\hline & $X(\mathrm{~mm})$ & $Y(m m)$ & $\mathbf{Z}(\mathrm{mm})$ & \\
\hline \multicolumn{5}{|l|}{ 1. Left SI seed } \\
\hline \multicolumn{5}{|l|}{ Contrast: $5>25 \mathrm{~cm} / \mathrm{s}$} \\
\hline Left PostCG (35), aSMG (22) & -38 & -36 & 42 & 57 \\
\hline \multicolumn{5}{|l|}{ Contrast: $5>65 \mathrm{~cm} / \mathrm{s}$} \\
\hline Right pMTG & 70 & -22 & -12 & 155 \\
\hline Right Cerebellum 6 & 34 & -54 & -24 & 73 \\
\hline Right AG & 60 & -52 & 26 & 64 \\
\hline \multicolumn{5}{|l|}{ Contrast: $25>65 \mathrm{~cm} / \mathrm{s}$} \\
\hline Left iLOC (140) & -36 & -78 & 2 & 140 \\
\hline Right iLOC (490), sLOC (138), FG (64) & 40 & -82 & -6 & 692 \\
\hline Right FG (53), Right Cerebellum 6 (46) & 34 & -60 & -22 & 99 \\
\hline \multicolumn{5}{|l|}{ 2. Left SII seed } \\
\hline \multicolumn{5}{|l|}{ Contrast: $25>65 \mathrm{~cm} / \mathrm{s}$} \\
\hline Left SPL & -32 & -52 & 68 & 42 \\
\hline Right sLOC & 36 & -84 & 18 & 42 \\
\hline \multicolumn{5}{|l|}{ 3. Right SI seed } \\
\hline \multicolumn{5}{|l|}{ Contrast: $5>65 \mathrm{~cm} / \mathrm{s}$} \\
\hline Left iLOC & -42 & -72 & 2 & 78 \\
\hline Right pMTG & 64 & -24 & -4 & 40 \\
\hline \multicolumn{5}{|l|}{ Contrast: $5<65 \mathrm{~cm} / \mathrm{s}$} \\
\hline Right IC & 40 & -4 & -6 & 109 \\
\hline \multicolumn{5}{|l|}{ Contrast: $25>65 \mathrm{~cm} / \mathrm{s}$} \\
\hline Left iLOC & -38 & -78 & 0 & 96 \\
\hline Right iLOC & 46 & -82 & -4 & 298 \\
\hline \multicolumn{5}{|l|}{ Contrast: $25<65 \mathrm{~cm} / \mathrm{s}$} \\
\hline Left Cerebellum Crus ॥ & -38 & -66 & -54 & 34 \\
\hline \multicolumn{5}{|l|}{ 4. Right SII seed } \\
\hline \multicolumn{5}{|l|}{ Contrast: $5<65 \mathrm{~cm} / \mathrm{s}$} \\
\hline Right SFG & 18 & 8 & 66 & 76 \\
\hline \multicolumn{5}{|l|}{ Contrast: $25>65 \mathrm{~cm} / \mathrm{s}$} \\
\hline Left SPL & -30 & -58 & 62 & 147 \\
\hline \multicolumn{5}{|l|}{ Contrast: $25<65 \mathrm{~cm} / \mathrm{s}$} \\
\hline Right SFG & 18 & 12 & 48 & 50 \\
\hline
\end{tabular}

PostCG, Postcentral Gyrus; aSMG, anterior Supramarginal Gyrus; pMTG, posterior Middle Temporal Gyrus; AG, Angular Gyrus; iLOC, inferior Lateral Occipital Cortex; sLOC, superior Lateral Occipital Cortex; FG, Fusiform Gyrus; SPL, Superior Parietal Lobule; IC, Insular Cortex; SFG, Superior Frontal Gyrus.

Our ROI-to-ROI results presented greater similarity of FC across the three velocities in the contralateral hemisphere. The only difference in connection strength was between the right DLPFC, and the right thalamus, and the $5 \mathrm{~cm} / \mathrm{s}$ velocity evoked weaker FC than did the $25 \mathrm{~cm} / \mathrm{s}$. The right DLPFC has been associated with many high-level functions, such as alerting, cognitive control, emotional regulation, and working memory (Critchley et al., 2001; Mannarelli et al., 2015; Schaal et al., 2017; Wang et al., 2018; Yang et al., 2018). A case report has shown that a patient with a thalamic lesion in the region of the right intralaminar nuclei was conspicuously slow, inflexible, and lacked concentration, suggesting that the right thalamus is critical for healthy cognitive functions (Van Der Werf et al., 1999). Our 

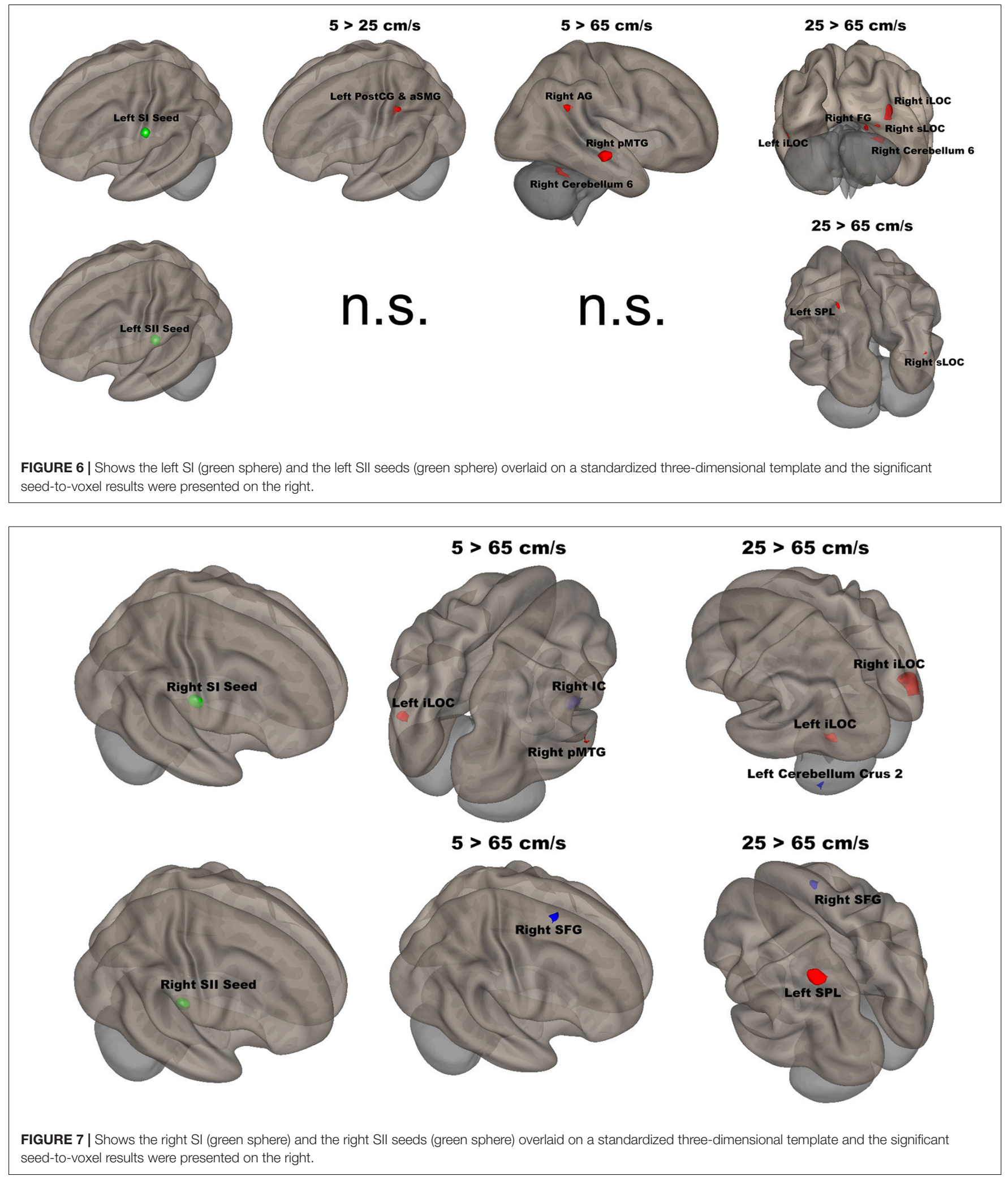

paradigm used a fixed block length. Thus, there were more air pulses delivered for the $25 \mathrm{~cm} / \mathrm{s}$ blocks than for the $5 \mathrm{~cm} / \mathrm{s}$ blocks. The $5 \mathrm{~cm} / \mathrm{s}$ velocity, which had the lowest temporal density of tactile stimulation, required little attention during the task, leading to weaker FC between the attention region (right DLPFC) and important hub region (right thalamus). Interestingly, there 
were no differences in the FC connection strength between the right DLPFC and the right thalamus for contrasts of $5 \mathrm{vs} 65 \mathrm{~cm} / \mathrm{s}$, or $25 \mathrm{vs} 65 \mathrm{~cm} / \mathrm{s}$. This result indicated that a $65 \mathrm{~cm} / \mathrm{s}$ velocity, the highest velocity used in this study, exceeded the optimal range of velocity. The optimal velocity range for moving tactile stimuli was $3-30 \mathrm{~cm} / \mathrm{s}$ for the hand and $3-25 \mathrm{~cm} / \mathrm{s}$ for the face (Langford et al., 1973; Whitsel et al., 1978, 1986; Dreyer et al., 1979; Essick et al., 1987, 1988; Edin et al., 1995). Additionally, the results of our previous study indicated that a velocity of $5 \mathrm{~cm} / \mathrm{s}$ evoked the most extensive brain activation (Custead et al., 2017), indicating that there were sufficient data from three runs for the lowest temporal density of pneumotactile stimulation $(5 \mathrm{~cm} / \mathrm{s})$ to evoke cortical activation. For $25-$ and $65-\mathrm{cm} / \mathrm{s}$ velocities, the higher temporal density of air-pulse stimulation did not elicit more BOLD responses in the brain, suggesting that adaptation or repetition-suppressing processes may play a role (Hollins et al., 1991; Popescu et al., 2013; Yang et al., 2014; Custead et al., 2017). Additionally, the $65-\mathrm{cm} / \mathrm{s}$ velocity exceeded the optimal range of velocity for the face and was processed differently in higher-order cortical levels of cortex in an animal study (Darian-Smith et al., 1984). High velocities have high temporal density, but have low perception accuracy (Lamb, 1983; Custead et al., 2017), whereas the $5-\mathrm{cm} / \mathrm{s}$ velocity might be processed as discrete stimuli to the facial skin, rather than as a constant motion across the skin (Wacker et al., 2011; Depeault et al., 2013). A recent study evaluated tactile pleasantness by stroking a soft brush over the skin and concluded that middle velocities, from 1 to $10 \mathrm{~cm} / \mathrm{s}$, were the preferred velocities, based on the pleasantness ratings (Ackerley et al., 2014). No participant in this study reported discomfort or pain sensation. Thus, painrelated neuronal networks did not influence our results.

In the "All ON" condition, the multichannel TAC-Cells were stimulated simultaneously. The contrasts of each velocity with the "All ON" condition revealed differences in FC strengths caused by the effects of the velocities of the tactile stimuli. For $5 \mathrm{~cm} / \mathrm{s}$ vs "All ON" conditions, there was reduced FC between the right SII and the right PPC. Our previous results showed bilateral activation patterns when comparing $5 \mathrm{~cm} / \mathrm{s}$ vs “All ON" (Custead et al., 2017). Our previous GLM results were limited to the strength of BOLD signals and could not determine the FC between a pair of cortical areas, while the present FC analysis allowed us to understand FC by calculation of Pearson's correlation coefficients using time courses from pairs of cortical areas. A previous fMRI study has reported the representations of six body parts (face, fingers, legs, shoulders, lips, and toes) in the superior PPC (Huang et al., 2012). The right SII is connected reciprocally with the right (ipsilateral) SI (Karhu and Tesche, 1999). The "All ON" condition contains the highest temporal density of pneumotactile stimuli, and the fast $A \beta$ fibers were used to carry the sensory information. The $5-\mathrm{cm} / \mathrm{s}$ velocity contained the lowest temporal density, and the slow C-tactile fibers were probably used to pass the sensory information. Therefore, the faster conduction from the peripheral nervous system (PNS) for the "All ON" condition allowed faster information flow between the right PPC and the right SII and led to stronger FC than the $5-\mathrm{cm} / \mathrm{s}$ velocity. For the $65 \mathrm{~cm} / \mathrm{s}$ vs "All ON" conditions, there was increased
FC between the right thalamus and bilateral SII. The $65-\mathrm{cm} / \mathrm{s}$ velocity is not optimal for evoking functional networks in brain supporting velocity encoding, but the $65-\mathrm{cm} / \mathrm{s}$ velocity elicited increased FC in the right thalamus. Our results support the role of the thalamus as an integrative hub for functional brain networks (Hwang et al., 2017). An early animal study found that SII receives substantial inputs from topographically appropriate regions within the ipsilateral ventrobasal nucleus and from the ipsilateral posterior group (Carvell and Simons, 1987), which indicated that SII in mice may complement the function of SI by helping to define the overall sensory context in which detailed tactile discriminations are made. Our findings suggested that the right SII was involved in both low and high velocities and might play an important role in discriminating the velocity of orofacial tactile stimuli (Carvell and Simons, 1987; Tommerdahl et al., 2005a). Moreover, there was no statistically significant difference in connection strength for the $25 \mathrm{~cm} / \mathrm{s}$ vs "All ON" conditions. This unexpected finding indicated that the three velocities were processed differently at the CNS-level, and that different processes at the PNS level might be the driving force. Determining how the three velocities were processed in the PNS was beyond the scope of the present study.

Our Seed-to-Voxel analyses were limited to four seeds only, since the bilateral SI and SII were most commonly activated during tactile stimulation (Karhu and Tesche, 1999; Simoes and Hari, 1999; Backes et al., 2000; Lin and Kajola, 2003; Simoes et al., 2003; Inui et al., 2004; Blatow et al., 2007; Dresel et al., 2008; Eickhoff et al., 2008; Garraghty et al., 2009; Tommerdahl et al., 2010; Hu et al., 2012; Popescu et al., 2013; Vahdat et al., 2014; Venkatesan et al., 2014; Avanzini et al., 2016). Although more seeds could be added, the power of this study would have been affected due to the relatively small number of participants. The changes in FC patterns for different velocities and four seeds (bilateral SI and SII) suggested that each velocity is unique, and might be used based on the sensitivity and spatial specificity needed for the specific neurotherapeutic applications.

The left (contralateral) SI seed had stronger FC with the left PostCG/aSMG in the comparison of 5 vs $25 \mathrm{~cm} / \mathrm{s}$. The left PostCG/aSMG were reported to demonstrate significant increases in BOLD signals for $5 \mathrm{~cm} / \mathrm{s}$ vs "All OFF" condition in our previous fMRI study (Custead et al., 2017). More specificially, the low velocity $(5 \mathrm{~cm} / \mathrm{s})$ evoked both stronger FC and BOLD signals in the left PostCG/aSMG than did the mid-range velocity $(25 \mathrm{~cm} / \mathrm{s})$. Lamb et al. reported that increases in stimulus velocity could lead to sufficient loss of spatiotemporal information to decrease discrimination accuracy (Lamb, 1983). FC was increased between the left SI seed and the right AG, right pMTG, and right cerebellum 6 for $5-\mathrm{cm} / \mathrm{s}$ velocity vs $65-\mathrm{cm} / \mathrm{s}$ velocity. The right AG has been related to numerical representation (Gobel et al., 2001). Our visual paradigm was a visual number countdown task. During the $5 \mathrm{~cm} / \mathrm{s}$ blocks, the number countdown task-evoked time courses in the right AG that correlated with the time courses of BOLD signals in the left SI. The stronger FC between the left SI and the right FG for $5-\mathrm{cm} / \mathrm{s}$ velocity vs $65-\mathrm{cm} / \mathrm{s}$ velocity indicated that temporal accuracy was higher for the slowest velocity. The right pMTG has been shown to be involved in the frontoparietal network, which positively modulated cognitive 
tasks (Jolles et al., 2013). The low velocity evoked the largest spatial extent of activation in the comparison of $5 \mathrm{~cm} / \mathrm{s}$ with the "All OFF" condition (Custead et al., 2017), which corresponded with the stronger FC between the left SI and right pMTG for $5-\mathrm{cm} / \mathrm{s}$ velocity vs $65-\mathrm{cm} / \mathrm{s}$ velocity. FC was increased between the left SI seed with the right FG, right sLOC, bilateral iLOC, and right cerebellum 6 for $25-\mathrm{cm} / \mathrm{s}$ velocity as compared to $65-$ $\mathrm{cm} / \mathrm{s}$ velocity. The right $\mathrm{FG}$, right $\mathrm{sLOC}$, and bilateral iLOC cover the spatial extent of the occipital lobe, suggesting more involvement of visual attention for $25-\mathrm{cm} / \mathrm{s}$ velocity than for 65 $\mathrm{cm} / \mathrm{s}$ velocity. The right cerebellum 6 was activated for both 5 vs $65 \mathrm{~cm} / \mathrm{s}$ and 25 vs $65 \mathrm{~cm} / \mathrm{s}$. The right cerebellum 6 region is located at the right lobule VI of the cerebellum and is involved in the sensorimotor network (Bellebaum and Daum, 2007; Habas et al., 2009; Stoodley et al., 2012; Picerni et al., 2013; Guo et al., 2015), in line with our findings.

The left SII showed significantly increased FC only between the left SPL and right sLOC for $25 \mathrm{~cm} / \mathrm{s}$ as compared to $65 \mathrm{~cm} / \mathrm{s}$. There were clear differences in FC patterns between the left SI and SII, in agreement with other studies (Backes et al., 2000). There were more similarities in FC patterns between 5 and $25 \mathrm{~cm} / \mathrm{s}$ conditions in the left SII than for the left SI. Both velocities were within the optimal velocity range. The differences in FC between 25 and $65 \mathrm{~cm} / \mathrm{s}$ conditions is likely to be driven by the $25-\mathrm{cm} / \mathrm{s}$ velocity, since there was no difference in FC for 5 vs $65 \mathrm{~cm} / \mathrm{s}$ or 5 vs $25 \mathrm{~cm} / \mathrm{s}$. The left SII has been suggested to participate in the high-order processing of somatosensory stimuli (Backes et al., 2000), which was supported by our results.

There was significantly increased FC between the right SI seed and the left iLOC and right pMTG, as well as decreased FC between the right SI seed and right IC for $5 \mathrm{~cm} / \mathrm{s}$ as compared to $65 \mathrm{~cm} / \mathrm{s}$. The right IC has been shown to be involved in inhibiting sensorimotor responses as part of the attention network (Corbetta and Shulman, 2002; Custead et al., 2017). The fastest velocity with the highest temporal density led to more repetition and required more control over response suppression. FC between the right SI seed and the bilateral iLOC was significantly increased, and FC between the right SI and the left cerebellum crus II was significantly decreased, for $25 \mathrm{~cm} / \mathrm{s}$ as compared to $65 \mathrm{~cm} / \mathrm{s}$. The cerebellar involvement is consistent with the putative role of the cerebellum in feedforward control of sensory-guided movements at $5 \mathrm{~cm} / \mathrm{s}$ (Custead et al., 2017).

The right SII showed significantly weaker FC with the right SFG for both 5 vs $65 \mathrm{~cm} / \mathrm{s}$ and 25 vs $65 \mathrm{~cm} / \mathrm{s}$, but there was no difference for 5 vs $25 \mathrm{~cm} / \mathrm{s}$ conditions. Thus, the noted FC difference was driven by the highest velocity. The right SFG plays a role in executive function, supporting bottom-up attention (Jolles et al., 2013). The increases in velocity required more bottom-up attention or alertness. Moreover, the right SII showed significantly stronger FC with the left SPL and weaker FC with the right SFG for $25 \mathrm{~cm} / \mathrm{s}$ as compared to $65 \mathrm{~cm} / \mathrm{s}$. Somatosensory stimuli are processed in the left SPL, which is also involved in sensorimotor integration (Ruben et al., 2001). Weaker FC with the left SPL for 25 than for $65 \mathrm{~cm} / \mathrm{s}$ might be due to the higher temporal density of the highest velocity stimulation. In other words, there are more somatosensory stimuli delivered in $20 \mathrm{~s}$ for the $65 \mathrm{~cm} / \mathrm{s}$ than for either 5 or $25 \mathrm{~cm} / \mathrm{s}$ stimuli.

\section{Laterality}

Both contralateral and ipsilateral FC of both SI and SII during unilateral or bilateral activation have been reported in animal (Tommerdahl et al., 2005a,b) and human studies (Tommerdahl et al., 2006; Akselrod et al., 2017). Neurons in SII most often have bilateral receptive fields, unlike neurons in SI (Whitsel et al., 1969). Our ROI-to-ROI results showed stronger FC between the right thalamus and bilateral SII for $65 \mathrm{~cm} / \mathrm{s}$ as compared to the "All ON" condition, supporting the view of the involvement of bilateral SII in unilateral stimulation. The present study demonstrated that FC was reduced between the right $\mathrm{PPC}$ and the right SII for $5 \mathrm{~cm} / \mathrm{s}$ as compared to the "All ON" condition, suggesting that right SII activity evoked by the slow velocity is critical for neuronal encoding of orofacial tactile perception of velocity. We also observed changes in FC in both hemispheres, in alignment with our previous report on bilateral cortical responses (Custead et al., 2017). The different velocities evoked different brain connectivity patterns that were mostly noted in the right (contralateral) hemisphere, supporting the involvement of interhemispheric connections for complex pneumotactile stimulation.

\section{Limitations}

This study had several limitations. First, a major limitation was that the imaging modality measured relatively slow hemodynamic responses, in the order of seconds. FMRI data can provide some indirect measures to decode how the sensory system perceives stimuli with different velocities. However, humans can make sensory decisions in less than $200 \mathrm{~ms}$, which relies primarily on rapid synaptic neurotransmission on a time scale of milliseconds (Kohn et al., 2002). Thus, electrophysiologybased imaging approaches (i.e., MEG, EEG) are more suitable for studying the dynamic information of this rapidly changing system (Puts et al., 2019). Second, the relatively small sample size and wider age range of our participants could have limited the power of this study. Third, the FC analyses in the present study could not allow conclusions about the causal relationships between cortical regions and about whether the cortical network supporting higher-order processing of the facial tactile stimuli involved serial or parallel processing. Lastly, no behavioral measures were collected to assess individual differences in perception ability.

\section{CONCLUSION AND FUTURE DIRECTIONS}

In this study, cortical connectivity patterns associated with various tactile stimulation velocities were studied using fMRI, which has not been reported previously. Our results demonstrated both similarities and differences in the neuronal networks across the three velocities. Animal and human studies have shown that passively evoked sensory stimulation can enhance neuronal activity after stroke (Whitaker et al., 2007). Therefore, the present study has implications for applying passive pneumotactile stimuli, with various velocities, to bolster functional recovery during sensorimotor rehabilitation. 
For instance, if this is combined with physical therapy for stroke patients or brain-injury survivors, it might induce more brain plasticity during sensorimotor rehabilitation (Small et al., 2002; Luft et al., 2005; da Guarda and Conforto, 2014). In future, a large cohort study should investigate age- and sex-effects on the perception of velocity (Venkatesan et al., 2015). Moreover, the effect of placement of TAC-Cells (right side vs left side, etc.) on the face should be investigated. Finally, stroke survivors could be included as a comparison group in future studies. Rehabilitation protocols for stroke survivors can be designed using the Galileo system, and the efficacy thereof could be assessed using fMRI, or MEG, or both.

\section{DATA AVAILABILITY STATEMENT}

The raw data supporting the conclusions of this article will be made available by the authors, without undue reservation, to any qualified researcher.

\section{ETHICS STATEMENT}

The study was reviewed and approved by the Institutional Review Board at University of Nebraska-Lincoln. Written informed consent was obtained from each participant in accordance with the Declaration of Helsinki.

\section{REFERENCES}

Ackerley, R., Carlsson, I., Wester, H., Olausson, H., and Backlund Wasling, H. (2014). Touch perceptions across skin sites: differences between sensitivity, direction discrimination and pleasantness. Front. Behav. Neurosci. 8:54. doi: 10.3389/fnbeh.2014.00054

Ackerley, R., Hassan, E., Curran, A., Wessberg, J., Olausson, H., and Mcglone, F. (2012). An fMRI study on cortical responses during active self-touch and passive touch from others. Front. Behav. Neurosci. 6:51. doi: 10.3389/fnbeh. 2012.00051

Akselrod, M., Martuzzi, R., Serino, A., Van Der Zwaag, W., Gassert, R., and Blanke, O. (2017). Anatomical and functional properties of the foot and leg representation in areas $3 \mathrm{~b}, 1$ and 2 of primary somatosensory cortex in humans: a 7T fMRI study. Neuroimage 159, 473-487.

Avanzini, P., Abdollahi, R. O., Sartori, I., Caruana, F., Pelliccia, V., Casaceli, G., et al. (2016). Four-dimensional maps of the human somatosensory system. Proc. Natl. Acad. Sci. U.S.A. 113, E1936-E1943.

Avivi-Arber, L., Martin, R., Lee, J. C., and Sessle, B. J. (2011). Face sensorimotor cortex and its neuroplasticity related to orofacial sensorimotor functions. Arch. Oral Biol. 56, 1440-1465.

Backes, W., Mess, W., Van Kranen-Mastenbroek, V., and Reulen, J. (2000). Somatosensory cortex responses to median nerve stimulation: fMRI effects of current amplitude and selective attention. Clin. Neurophysiol. 111, 1738-1744.

Backlund, H., Wiklund Fernström, K., Starck, G., Ekholm, S., and Olausson, H. (2003). "Directional sensibility of the human hairy skin: an fMRI study," in Proceedings of the Abstract for the 33rd Annual Meeting of the Society for Neuroscience, New Orleans, LA.

Backlund Wasling, H., Lundblad, L., Loken, L., Wessberg, J., Wiklund, K., Norrsell, U., et al. (2008). Cortical processing of lateral skin stretch stimulation in humans. Exp. Brain Res. 190, 117-124.

Barlow, S. M. (1987). Mechanical frequency detection thresholds in the human face. J. Exp. Neurol. 96, 253-261.

Barlow, S. M. (1998). Real time modulation of speech-orofacial motor performance by means of motion sense. J. Commun. Disord. 31, 511-534.

\section{AUTHOR CONTRIBUTIONS}

YW proposed and performed connectivity analysis, and drafted the manuscript. SB contributed to the conception, design, and data collection of the study, and revising the manuscript critically for important intellectual content. RC and $\mathrm{HO}$ carried out the experiment and data collection. FS organized and pre-processed the data. All authors read and approved the submitted version and agree to be accountable for all aspects of the work.

\section{FUNDING}

This work was supported by funds from the Barkley Trust (SB and YW), Nebraska Tobacco Settlement Biomedical Research Development, College of Education and Human Sciences, and the Office of Research and Economic Development.

\section{ACKNOWLEDGMENTS}

We thank the families for their participation. We also thank the supports for undergraduate research assistants from the UNL UCARE program funded in part by gifts from the Pepsi Quasi Endowment and Union Bank \& Trust. We also thank Editage (www.editage.com) for English language editing.

Barlow, S. M., and Bradford, P. T. (1996). Comparison of perioral reflex modulation in the upper and lower lip. J. Speech Lang. Hear. Res. 39, 55-75.

Barlow, S. M., and Estep, M. (2006). Central pattern generation and the motor infrastructure for suck, respiration, and speech. J. Commun. Disord. 39, 366-380.

Barlow, S. M., and Stumm, S. (2010). "Speech production: adult," in Encyclopedia of Neuroscience, ed. L. R. Squire (Amsterdam: Elsevier Ltd), 247-254.

Behzadi, Y., Restom, K., Liau, J., and Liu, T. T. (2007). A component based noise correction method (CompCor) for BOLD and perfusion based fMRI. Neuroimage 37, 90-101.

Bellebaum, C., and Daum, I. (2007). Cerebellar involvement in executive control. Cerebellum 6, 184-192.

Bjornsdotter, M., Loken, L., Olausson, H., Vallbo, A., and Wessberg, J. (2009). Somatotopic organization of gentle touch processing in the posterior insular cortex. J. Neurosci. 29, 9314-9320.

Blatow, M., Nennig, E., Durst, A., Sartor, K., and Stippich, C. (2007). fMRI reflects functional connectivity of human somatosensory cortex. Neuroimage 37, 927-936.

Carvell, G. E., and Simons, D. J. (1987). Thalamic and corticocortical connections of the second somatic sensory area of the mouse. J. Compar. Neurol. 265, 409-427.

Corbetta, M., and Shulman, G. L. (2002). Control of goal-directed and stimulusdriven attention in the brain. Nat. Rev. Neurosci. 3, 201-215.

Critchley, H. D., Mathias, C. J., and Dolan, R. J. (2001). Neural activity in the human brain relating to uncertainty and arousal during anticipation. Neuron 29, 537-545.

Custead, R., Oh, H., Rosner, A. O., and Barlow, S. M. (2015). Adaptation of the cortical somatosensory evoked potential following pulsed pneumatic stimulation of the lower face in adults. Brain Res. 1622, 81-90.

Custead, R., Oh, H., Wang, Y., and Barlow, S. (2017). Brain encoding of saltatory velocity through a pulsed pneumotactile array in the lower face. Brain Res. 1677, 58-73.

da Guarda, S. N. F., and Conforto, A. B. (2014). Effects of somatosensory stimulation on corticomotor excitability in patients with unilateral cerebellar infarcts and healthy subjects-preliminary results. Cereb. Ataxias 1:16. 
Darian-Smith, I., Goodwin, A., Sugitani, M., and Heywood, J. (1984). "The tangible features of textured surfaces: their representation in the monkey's somatosensory cortex," in Dynamic Aspects of Neocortical Function, eds G. M. Edelman, W. E. Gall, and W. M. Cowan (New York, NY: Wiley), 475-500.

Depeault, A., Meftah, El, M., and Chapman, C. E. (2013). Neuronal correlates of tactile speed in primary somatosensory cortex. J. Neurophysiol. 110, 1554-1566.

Dresel, C., Parzinger, A., Rimpau, C., Zimmer, C., Ceballos-Baumann, A. O., and Haslinger, B. (2008). A new device for tactile stimulation during fMRI. Neuroimage 39, 1094-1103.

Dreyer, D. A., Duncan, G. H., Wong, C. L., and Whitsel, B. L. (1979). Factors influencing capacity to judge direction of tactile stimulus movement on the face. J. Dent. Res. 58, 2052-2057.

Edin, B. B., Essick, G. K., Trulsson, M., and Olsson, K. A. (1995). Receptor encoding of moving tactile stimuli in humans. I. Temporal pattern of discharge of individual low-threshold mechanoreceptors. J. Neurosci. 15, 830-847.

Eickhoff, S. B., Grefkes, C., Fink, G. R., and Zilles, K. (2008). Functional lateralization of face, hand, and trunk representation in anatomically defined human somatosensory areas. Cereb. Cortex 18, 2820-2830.

Essick, G., Franzen, O., and Whitsel, B. (1988). Discrimination and scaling of velocity of stimulus motion across the skin. Somatos. Motor Res. 6, 21-40.

Essick, G., Starr, G., Dolan, P., and Afferica, T. (1987). Evaluation of directional sensitivity within the mental nerve distribution. J. Dental Res. 93, 157-157.

Ferezou, I., Haiss, F., Gentet, L. J., Aronoff, R., Weber, B., and Petersen, C. C. (2007). Spatiotemporal dynamics of cortical sensorimotor integration in behaving mice. Neuron 56, 907-923.

Friston, K. J., Worsley, K. J., Frackowiak, R. S., Mazziotta, J. C., and Evans, A. C. (1994). Assessing the significance of focal activations using their spatial extent. Hum. Brain Mapp. 1, 210-220.

Garraghty, P. E., Pons, T. P., and Kaas, J. H. (2009). Ablations of areas 3b (SI Proper) and $3 \mathrm{a}$ of somatosensory cortex in marmosets deactivate the second and parietal ventral somatosensory areas. Somatos. Motor Res. 7, 125-135.

Gobel, S., Walsh, V., and Rushworth, M. F. (2001). The mental number line and the human angular gyrus. Neuroimage 14, 1278-1289.

Grabski, K., Lamalle, L., Vilain, C., Schwartz, J. L., Vallee, N., Tropres, I., et al. (2012). Functional MRI assessment of orofacial articulators: neural correlates of lip, jaw, larynx, and tongue movements. Hum. Brain Mapp. 33, 2306-2321.

Grodd, W., Hulsmann, E., Lotze, M., Wildgruber, D., and Erb, M. (2001). Sensorimotor mapping of the human cerebellum: fMRI evidence of somatotopic organization. Hum. Brain Mapp. 13, 55-73.

Guo, W., Liu, F., Chen, J., Wu, R., Zhang, Z., Yu, M., et al. (2015). Resting-state cerebellar-cerebral networks are differently affected in first-episode, drug-naive schizophrenia patients and unaffected siblings. Sci. Rep. 5:17275.

Habas, C., Kamdar, N., Nguyen, D., Prater, K., Beckmann, C. F., Menon, V., et al. (2009). Distinct cerebellar contributions to intrinsic connectivity networks. J. Neurosci. 29, 8586-8594.

Hermundstad, A. M., Bassett, D. S., Brown, K. S., Aminoff, E. M., Clewett, D., Freeman, S., et al. (2013). Structural foundations of resting-state and task-based functional connectivity in the human brain. Proc. Natl. Acad. Sci. U.S.A. 110, 6169-6174.

Hollins, M., Delemos, K. A., and Goble, A. K. (1991). Vibrotactile adaptation on the face. Percept. Psychophys. 49, 21-30.

Hu, L., Zhang, Z. G., and Hu, Y. (2012). A time-varying source connectivity approach to reveal human somatosensory information processing. Neuroimage $62,217-228$.

Huang, R. S., Chen, C. F., Tran, A. T., Holstein, K. L., and Sereno, M. I. (2012). Mapping multisensory parietal face and body areas in humans. Proc. Natl. Acad. Sci. U.S.A. 109, 18114-18119.

Hwang, K., Bertolero, M. A., Liu, W. B., and D'esposito, M. (2017). The human thalamus is an integrative hub for functional brain networks. J. Neurosci. 37, 5594-5607.

Ibáñez, V., Deiber, M.-P., Sadato, N., Toro, C., Grissom, J., Woods, R. P., et al. (1995). Effects of stimulus rate on regional cerebral blood flow after median nerve stimulation. Brain 118, 1339-1351.

Ing, A., and Schwarzbauer, C. (2014). Cluster size statistic and cluster mass statistic: two novel methods for identifying changes in functional connectivity between groups or conditions. PLoS ONE 9:e98697. doi: 10.1371/journal.pone.0098697

Inui, K., Wang, X., Tamura, Y., Kaneoke, Y., and Kakigi, R. (2004). Serial processing in the human somatosensory system. Cereb. Cortex 14, 851-857.
Jenkins, B. A., and Lumpkin, E. A. (2017). Developing a sense of touch. Development 144, 4078-4090.

Johansson, R. S., and Olsson, K. A. (1976). Microelectrode recordings from human oral mechanoreceptors. Brain Res. 118, 307-311.

Johansson, R. S., Trulsson, M., Olsson, K., and Westberg, K.-G. (1988). Mechanoreceptor activity from the human face and oral mucosa. Exp. Brain Res. 72, 204-208.

Jolles, D. D., Van Buchem, M. A., Crone, E. A., and Rombouts, S. A. (2013). Functional brain connectivity at rest changes after working memory training. Hum. Brain Mapp. 34, 396-406.

Karhu, J., and Tesche, C. (1999). Simultaneous early processing of sensory input in human primary (SI) and secondary (SII) somatosensory cortices. J. Neurophysiol. 81, 2017-2025.

Khoshnejad, M., Piche, M., Saleh, S., Duncan, G., and Rainville, P. (2014). Serial processing in primary and secondary somatosensory cortex: a DCM analysis of human fMRI data in response to innocuous and noxious electrical stimulation. Neurosci. Lett. 577, 83-88.

Kohn, A., Metz, C., Tommerdahl, M. A., and Whitsel, B. L. (2002). Stimulusevoked modulation of sensorimotor pyramidal neuron EPSPs. J. Neurophysiol. 88, 3331-3347.

Krupa, D. J., Matell, M. S., Brisben, A. J., Oliveira, L. M., and Nicolelis, M. A. (2001). Behavioral properties of the trigeminal somatosensory system in rats performing whisker-dependent tactile discriminations. J. Neurosci. 21, 57525763.

Ladda, A. M., Pfannmoeller, J. P., Kalisch, T., Roschka, S., Platz, T., Dinse, H. R., et al. (2014). Effects of combining 2 weeks of passive sensory stimulation with active hand motor training in healthy adults. PLoS ONE 9:e84402. doi: 10.1371/ journal.pone. 0084402

Lamb, G. D. (1983). Tactile discrimination of textured surfaces: psychophysical performance measurements in humans. J. Physiol. 338, 551-565.

Langford, N., Hall, R. J., and Monty, R. A. (1973). Cutaneous perception of a track produced by a moving point across the skin. J. Exp. Psychol. 97, 59-63.

Lin, Y. Y., and Kajola, M. (2003). Neuromagnetic somatosensory responses to natural moving tactile stimulation. Can. J. Neurol. Sci. 30, 31-35.

Luft, A. R., Manto, M.-U., and Taib, N. O. B. (2005). Modulation of motor cortex excitability by sustained peripheral stimulation: the interaction between the motor cortex and the cerebellum. Cerebellum 4:90.

Lundblad, L. C., Olausson, H. W., Hermansson, A. K., and Wasling, H. B. (2011). Cortical processing of tactile direction discrimination based on spatiotemporal cues in man. Neurosci. Lett. 501, 45-49.

Mannarelli, D., Pauletti, C., Grippo, A., Amantini, A., Augugliaro, V., Curra, A., et al. (2015). The role of the right dorsolateral prefrontal cortex in phasic alertness: evidence from a contingent negative variation and repetitive transcranial magnetic stimulation study. Neural Plast. 2015:410785.

Miyamoto, J. J., Honda, M., Saito, D. N., Okada, T., Ono, T., Ohyama, K., et al. (2006). The representation of the human oral area in the somatosensory cortex: a functional MRI study. Cereb. Cortex 16, 669-675.

Moore, C. I., Nelson, S. B., and Sur, M. (1999). Dynamics of neuronal processing in rat somatosensory cortex. Trends Neurosci. 22, 513-520.

Moulton, E. A., Pendse, G., Morris, S., Aiello-Lammens, M., Becerra, L., and Borsook, D. (2009). Segmentally arranged somatotopy within the face representation of human primary somatosensory cortex. Hum. Brain Mapp. 30, $757-765$.

Nasir, S. M., Darainy, M., and Ostry, D. J. (2013). Sensorimotor adaptation changes the neural coding of somatosensory stimuli. J. Neurophysiol. 109, 2077-2085.

Nordin, M. (1990). Low-threshold mechanoreceptive and nociceptive units with unmyelinated (C) fibres in the human supraorbital nerve. J. Physiol. 426, 229-240.

Norrsell, U., and Olausson, H. (1994). Spatial cues serving the tactile directional sensibility of the human forearm. J. Physiol. 478(Pt 3), 533-540.

Nudo, R. J. (2013). Recovery after brain injury: mechanisms and principles. Front. Hum. Neurosci. 7:887. doi: 10.3389/fnhum.2013.00887

Oh, H., Custead, R., Wang, Y., and Barlow, S. (2017). Neural encoding of saltatory pneumotactile velocity in human glabrous hand. PLOS ONE 12:e0183532. doi: 10.1371/journal.pone.0183532

Pastor, M. A., Day, B. L., Macaluso, E., Friston, K. J., and Frackowiak, R. S. (2004). The functional neuroanatomy of temporal discrimination. J. Neurosci. $24,2585-2591$. 
Paus, R., Schmelz, M., Biro, T., and Steinhoff, M. (2006). Frontiers in pruritus research: scratching the brain for more effective itch therapy. J. Clin. Invest. 116, 1174-1186.

Pearson, K. (2000). Motor systems. Curr. Opin. Neurobiol. 10, 649-654.

Picerni, E., Petrosini, L., Piras, F., Laricchiuta, D., Cutuli, D., Chiapponi, C., et al. (2013). New evidence for the cerebellar involvement in personality traits. Front. Behav. Neurosci. 7:133. doi: 10.3389/fnbeh.2013.00133

Popescu, E. A., Barlow, S. M., Venkatesan, L., Wang, J., and Popescu, M. (2013). Adaptive changes in the neuromagnetic response of the primary and association somatosensory areas following repetitive tactile hand stimulation in humans. Hum. Brain Mapp. 34, 1415-1426.

Puts, N. A. J., Edden, R. A. E., Muthukumaraswamy, S., Singh, K. D., and Mcgonigle, D. J. (2019). Induced and evoked properties of vibrotactile adaptation in the primary somatosensory cortex. Neural Plast. 2019:5464096.

Reed, C. L., Shoham, S., and Halgren, E. (2004). Neural substrates of tactile object recognition: an fMRI study. Hum. Brain Mapp. 21, 236-246.

Ruben, J., Schwiemann, J., Deuchert, M., Meyer, R., Krause, T., Curio, G., et al. (2001). Somatotopic organization of human secondary somatosensory cortex. Cereb. Cortex 11, 463-473.

Sanes, J. N., and Donoghue, J. P. (2000). Plasticity and primary motor cortex. Annu. Rev. Neurosci. 23, 393-415.

Schaal, N. K., Kretschmer, M., Keitel, A., Krause, V., Pfeifer, J., and Pollok, B. (2017). The significance of the right dorsolateral prefrontal cortex for pitch memory in non-musicians depends on baseline pitch memory abilities. Front. Neurosci. 11:677. doi: 10.3389/fnins.2017.00677

Sessle, B., Adachi, K., Avivi-Arber, L., Lee, J., Nishiura, H., Yao, D., et al. (2007). Neuroplasticity of face primary motor cortex control of orofacial movements. Arch. Oral Biol. 52, 334-337.

Sessle, B. J., Yao, D., Nishiura, H., Yoshino, K., Lee, J. C., Martin, R. E., et al. (2005). Properties and plasticity of the primate somatosensory and motor cortex related to orofacial sensorimotor function. Clin. Exp. Pharmacol. Physiol. 32, 109-114.

Simoes, C., and Hari, R. (1999). Relationship between responses to contra- and ipsilateral stimuli in the human second somatosensory cortex SII. Neuroimage $10,408-416$

Simoes, C., Jensen, O., Parkkonen, L., and Hari, R. (2003). Phase locking between human primary and secondary somatosensory cortices. Proc. Natl. Acad. Sci. U.S.A. 100, 2691-2694.

Small, S., Hlustik, P., Noll, D., Genovese, C., and Solodkin, A. (2002). Cerebellar hemispheric activation ipsilateral to the paretic hand correlates with functional recovery after stroke. Brain 125, 1544-1557.

Smith, A. (2016). The control of orofacial movements in speech. Crit. Rev. Oral Biol. Med. 3, 233-267.

Stephan, K. E., Mattout, J., David, O., and Friston, K. J. (2006). Models of functional neuroimaging data. Curr. Med. Imaging Rev. 2, 15-34.

Stevens, M. C. (2009). The developmental cognitive neuroscience of functional connectivity. Brain Cognit. 70, 1-12.

Stoodley, C. J., Valera, E. M., and Schmahmann, J. D. (2012). Functional topography of the cerebellum for motor and cognitive tasks: an fMRI study. Neuroimage 59, 1560-1570.

Tomita, A., Kato, T., Sato, F., Haque, T., Oka, A., Yamamoto, M., et al. (2012). Somatotopic direct projections from orofacial areas of primary somatosensory cortex to pons and medulla, especially to trigeminal sensory nuclear complex, in rats. Neuroscience 200, 166-185.

Tommerdahl, M., Favorov, O. V., and Whitsel, B. L. (2010). Dynamic representations of the somatosensory cortex. Neurosci. Biobehav. Rev. 34, 160-170.

Tommerdahl, M., Simons, S. B., Chiu, J. S., Favorov, O., and Whitsel, B. (2005a). Response of SI cortex to ipsilateral, contralateral and bilateral flutter stimulation in the cat. BMC Neurosci. 6:29. doi: 10.1186/1471-2202-6-29

Tommerdahl, M., Simons, S. B., Chiu, J. S., Tannan, V., Favorov, O., and Whitsel, B. (2005b). Response of SII cortex to ipsilateral, contralateral and bilateral flutter stimulation in the cat. BMC Neurosci. 6:11. doi: 10.1186/1471-2202-6-11
Tommerdahl, M., Simons, S. B., Chiu, J. S., Favorov, O., and Whitsel, B. L. (2006). Ipsilateral input modifies the primary somatosensory cortex response to contralateral skin flutter. J. Neurosci. 26, 5970-5977.

Tononi, G., Edelman, G. M., and Sporns, O. (1998). Complexity and coherency: integrating information in the brain. Trends Cognit. Sci. 2, 474-484.

Vahdat, S., Darainy, M., and Ostry, D. J. (2014). Structure of plasticity in human sensory and motor networks due to perceptual learning. J. Neurosci. 34, 24512463.

Van Der Werf, Y. D., Weerts, J. G., Jolles, J., Witter, M. P., Lindeboom, J., and Scheltens, P. (1999). Neuropsychological correlates of a right unilateral lacunar thalamic infarction. J. Neurol. Neurosurg. Psychiatry 66, 36-42.

Venkatesan, L., Barlow, S. M., and Kieweg, D. (2015). Age-and sex-related changes in vibrotactile sensitivity of hand and face in neurotypical adults. Somatos. Motor Res. 32, 44-50.

Venkatesan, L., Barlow, S. M., Popescu, M., and Popescu, A. (2014). Integrated approach for studying adaptation mechanisms in the human somatosensory cortical network. Exp. Brain Res. 232, 3545-3554.

Wacker, E., Spitzer, B., Lutzkendorf, R., Bernarding, J., and Blankenburg, F. (2011). Tactile motion and pattern processing assessed with high-field FMRI. PLoS ONE 6:e24860. doi: 10.1371/journal.pone.0024860

Wang, J., Tian, J., Hao, R., Tian, L., and Liu, Q. (2018). Transcranial direct current stimulation over the right DLPFC selectively modulates subprocesses in working memory. PeerJ 6:e4906.

Whitaker, V. R., Cui, L., Miller, S., Yu, S. P., and Wei, L. (2007). Whisker stimulation enhances angiogenesis in the barrel cortex following focal ischemia in mice. J. Cereb. Blood Flow Metab. 27, 57-68.

Whitfield-Gabrieli, S., and Nieto-Castanon, A. (2012). Conn: a functional connectivity toolbox for correlated and anticorrelated brain networks. Brain Connect. 2, 125-141.

Whitsel, B., Dreyer, D., and Hollins, M. (1978). Representation of moving stimuli by somatosensory neurons. Fed. Proc. 37, 2223-2227.

Whitsel, B. L., Franzen, O., Dreyer, D. A., Hollins, M., Young, M., Essick, G. K., et al. (1986). Dependence of subjective traverse length on velocity of moving tactile stimuli. Somatosens. Res. 3, 185-196.

Whitsel, B. L., Petrucelli, L. M., and Werner, G. (1969). Symmetry and connectivity in the map of the body surface in somatosensory area II of primates. J. Neurophysiol. 32, 170-183.

Yang, J., Yu, Y., Kunita, A., Huang, Q., Wu, J., Sawamoto, N., et al. (2014). Tactile priming modulates the activation of the fronto-parietal circuit during tactile angle match and non-match processing: an fMRI study. Front. Hum. Neurosci. 8:926. doi: 10.3389/fnhum.2014.00926

Yang, L.-C., Ren, P., and Ma, Y.-Y. (2018). Anodal transcranial direct-current stimulation over the right dorsolateral prefrontal cortex influences emotional face perception. Neurosci. Bull. 34, 842-848.

Yeon, J., Kim, J., Ryu, J., Park, J. Y., Chung, S. C., and Kim, S. P. (2017). Human brain activity related to the tactile perception of stickiness. Front. Hum. Neurosci. 11:8. doi: 10.3389/fnhum.2017.00008

Zembrzycki, A., Chou, S. J., Ashery-Padan, R., Stoykova, A., and O'leary, D. D. (2013). Sensory cortex limits cortical maps and drives top-down plasticity in thalamocortical circuits. Nat. Neurosci. 16, 1060-1067.

Conflict of Interest: The authors declare that the research was conducted in the absence of any commercial or financial relationships that could be construed as a potential conflict of interest.

Copyright (c) 2020 Wang, Sibaii, Custead, Oh and Barlow. This is an open-access article distributed under the terms of the Creative Commons Attribution License (CC BY). The use, distribution or reproduction in other forums is permitted, provided the original author(s) and the copyright owner(s) are credited and that the original publication in this journal is cited, in accordance with accepted academic practice. No use, distribution or reproduction is permitted which does not comply with these terms. 